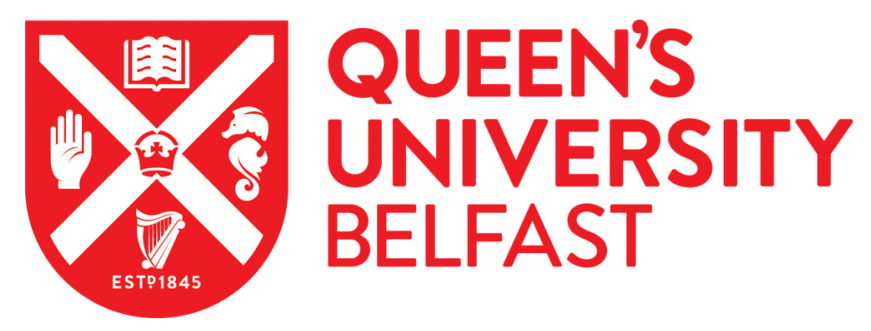

\title{
The performance of nickel-loaded lignite residue for steam reforming of toluene as the model compound of biomass gasification tar
}

Xiao, X., Liu, J., Gao, A., Zhouyu, M., Liu, B., Gao, M., Zhang, X., Lu, Q., \& Dong, C. (2017). The performance of nickel-loaded lignite residue for steam reforming of toluene as the model compound of biomass gasification tar. Journal of the Energy Institute. https://doi.org/10.1016/j.joei.2017.10.002

Published in:

Journal of the Energy Institute

Document Version:

Peer reviewed version

Queen's University Belfast - Research Portal:

Link to publication record in Queen's University Belfast Research Portal

Publisher rights

(C) 2017 Published by Elsevier Ltd on behalf of Energy Institute. This work is made available online in accordance with the publisher's policies. Please refer to any applicable terms of use of the publisher.

\section{General rights}

Copyright for the publications made accessible via the Queen's University Belfast Research Portal is retained by the author(s) and / or other copyright owners and it is a condition of accessing these publications that users recognise and abide by the legal requirements associated with these rights.

Take down policy

The Research Portal is Queen's institutional repository that provides access to Queen's research output. Every effort has been made to ensure that content in the Research Portal does not infringe any person's rights, or applicable UK laws. If you discover content in the Research Portal that you believe breaches copyright or violates any law, please contact openaccess@qub.ac.uk. 
Title: A combined connectivity mapping and pharmacoepidemiology approach to identify existing medications with breast cancer causing or preventing properties

Running title: Connectivity mapping for medication repurposing

Authors: John Busby ${ }^{1}$, Liam Murray ${ }^{1}$, Ken Mills ${ }^{2}$, Shu-Dong Zhang ${ }^{2,3}$, Fabio Liberante ${ }^{2}$, Chris Cardwell ${ }^{1}$

${ }^{1}$ Centre for Public Health, Queen's University Belfast, Belfast, UK

${ }^{2}$ Centre for Cancer Research and Cell Biology, Queen's University Belfast, Belfast, UK

${ }^{3}$ Northern Ireland Centre for Stratified Medicine, Biomedical Sciences Research Institute, University of Ulster, C-TRIC Building, Altnagelvin Area Hospital, Londonderry, UK

Correspondence: Dr. John Busby, Centre for Public Health, Queen's University Belfast, Institute for Clinical Science, Royal Victoria Hospital, Grosvenor Road, Belfast, BT12 6BJ, +442890971640, john.busby@qub.ac.uk

Keywords: drug discovery, connectivity mapping, pharmacoepidemiology, breast cancer

\section{Key points:}

- Several commonly used medications have been previously found to alter cancer risk. However identifying these is difficult.

- We applied a novel combined connectivity mapping and pharmacoepidemiological approach to identify new medications which alter breast cancer risk.

- Overall, our combined connectivity mapping and pharmacoepidemiological approach did not identify any additional medications which were substantially associated with breast cancer risk.

- Additional work exploring the causes of our null results are required to refine this methodology for future studies.

Manuscript word count: 3,051

Abstract word count: 219 


\section{Abstract}

Purpose: We applied a novel combined connectivity mapping and pharmacoepidemiological approach to identify medications which alter breast cancer risk.

Methods: The connectivity mapping process identified six potentially cancer-causing (meloxicam, azithromycin, rizatriptan, citalopram, rosiglitazone, verapamil) and four potentially cancerpreventing (bendroflumethiazide, sertraline, fluvastatin, budesonide) medications which were suitable for pharmacoepidemiological investigation. Within the UK Clinical Practice Research Datalink, we matched 45,147 breast cancer cases to one control per case based on age, year and GP practice. Medication use was determined from electronic prescribing records. We used conditional logistic regression to calculate odds ratios (ORs) for the association between medication use and cancer risk after adjustment for comorbidities, lifestyle factors, deprivation and other medication use.

Results: Bendroflumethiazide was associated with increased breast cancer risk (OR: 1.11; $95 \% \mathrm{Cl}$ : $1.06,1.15)$ however the connectivity mapping exercise predicted this medication would reduce risk. There were no statistically significant associations for any of the other candidate medications, with ever use ORs ranging from $0.93(95 \% \mathrm{Cl}: 0.78,1.11)$ for azithromycin to $1.16(95 \% \mathrm{Cl}: 0.0 .99,1.37)$ for verapamil.

Conclusions: In this instance, our combined connectivity mapping and pharmacoepidemiological approach did not identify any additional medications which were substantially associated with breast cancer risk. This could be due to limitations in the connectivity mapping, such as implausible dosage requirements, or the pharmacoepidemiology, such as residual confounding. 


\section{Introduction}

Breast cancer is the second most common cancer in the world, with 1.7 million new cases diagnosed each year.[1, 2] Survival rates are $85 \%$ at five years[3], with patients suffering reduced quality of life during treatment and recovery.[4-6] The disease places a large financial burden on society; in Europe it accounts for $€ 6.7$ billion in direct healthcare costs, and a further $€ 8.2$ billion in lost productivity and informal care costs.[7] Additional prevention and treatment strategies are required to improve patient outcomes and healthcare finances.

Recently, there has been much interest in exploring new uses for existing medications $[8,9]$, with notable successes in cancer treatment. For instance, aspirin has been shown to prevent colorectal cancer in certain high risk patients.[10] Identifying medications with previously unrecognised cancercausing properties could also improve prevention, particularly when prescribing is discretionary. For example, reports of higher breast cancer risk among hormone replacement therapy users have led to a sharp decline in its use.[11, 12] Despite the benefits of identifying existing medications which alter breast cancer risk, the large number of potential candidates for evaluation makes prioritising investigations difficult.

Connectivity mapping is an advanced bioinformatics technique that can be used to identify medications which mimic or reverse the gene-expression profiles induced by a disease.[13,14] It has previously been used to identify medications with anti-cancer properties. For instance, cimetidine has been discovered as a potential treatment for lung cancer[15], and rapamycin has been shown to overcome dexamethasone resistance in acute lymphoblastic leukaemia.[14] Pharmacoepidemiology allows the study of the association between medication use and outcomes in humans, quickly and at modest cost.[16] Therefore, a combination of connectivity mapping and pharmacoepidemiology could be used to rapidly identify medications which could alter breast cancer risk. This paper aims to apply this approach using population-based data from the UK. 


\section{Methods}

\section{Initial connectivity mapping screening and results}

Our application of the connectivity mapping is described briefly in Appendix 1, and more fully elsewhere.[17] Further details of this process are available upon request. The primary outcome of this was the 'connectivity score'[14], which is similar to a z-score from a standard normal distribution, and can be interpreted as the strength of agreement between the gene signature of the disease and medication. In this instance, a positive connectivity score indicates a medication with potential cancer-causing properties, whilst a negative score signifies a medication with potential cancer-preventing properties.

We initially identified 67 medications for inclusion in the analysis[17], but excluded 57 of these (Appendix 2) as they were rarely prescribed within primary care $(n=28,42 \%)$, already used in cancer treatment ( $n=21,31 \%)$, typically given in topical or nasal spray formulations which are unlikely to have a systemic effect $(n=5,7 \%)$, widely available over-the-counter $(n=2,3 \%)$, or already known to influence breast cancer risk $(n=1,1 \%)$. Of the ten remaining substances, six were identified as potentially increasing (meloxicam, azithromycin, rizatriptan, citalopram, rosiglitazone, verapamil) and four as potentially reducing (bendroflumethiazide, sertraline, fluvastatin, budesonide) the risk of breast cancer.

\section{Pharmacoepidemiology data}

We conducted a nested case-control study using the Clinical Practice Research Datalink (CPRD). The CPRD contains computerised medical records from 674 general practices (approximately $7 \%$ of the UK population).[18] Practices are audited by the CPRD and those meeting a predefined standard on data completeness and quality are deemed 'up to research standard', and included in future extracts. Data recorded includes patient demographics, clinical diagnoses (using Read codes) and prescription medication use. Previous research has found CPRD prescription and clinical information to be of high quality.[18-20] CPRD data was linked to the National Cancer Data Repository (NCDR)[21] to identify patients with a registry-confirmed breast cancer diagnosis, and to census information to derive Index of Multiple Deprivation (IMD) scores. The NCDR holds UK-wide data on cancer registration from a variety of sources including general practices, cancer screening programmes, NHS and private hospitals, and death certificates.[21] 
Ethical approval for all purely observational research using anonymised CPRD data was obtained from a National Research Ethics Service Committee (NRECS). The protocol for this study was approved by the CPRD Independent Scientific Advisory Committee (Ref: 15_212R), and has been made available to reviewers.

\section{Cases and controls}

In our primary analysis, cases were defined as patients with a first ever breast cancer diagnosis (ICD 10 code C50.0 to C50.9), identified from the NCDR cancer registry or GP records, between $1^{\text {st }}$ January 1995 and $31^{\text {st }}$ December 2010. This reflected a slight change from our initial analysis plan, which restricted cases to those with an NCDR-confirmed breast cancer diagnosis. We decided to use a broader case definition as recent evidence suggests that over $96 \%$ of breast cancers recorded within the CPRD can be validated using other data sources.[22] We conducted a secondary analysis restricted to NCDR-confirmed cases. Each case was matched to one control, who was breast cancer free on the cancer diagnosis date of the case, based on age (+/- one year if no exact match available), year of diagnosis and GP practice. The index date for the cases was their breast cancer diagnosis date. The index date of the controls was set equal to their matched case. The start of the exposure period was the latest of the patient's registration date at the practice, or when the practice's records were deemed to be 'up to research standard'. Cases and controls were included in the study if they had at least three years of 'up to research standard' medical records before their index date. This was to ensure that there was adequate time to ascertain exposure status and measure confounders. Where cases and controls had different lengths of follow-up, these were truncated to the shortest period within the matched set to avoid time-window bias.[23]

\section{Definition of exposure}

We used the British National Formulary (August 2016 version) to compile a list proprietary and generic drug names containing the compounds identified from the connectivity mapping (Appendix 3). Prescriptions in the year prior to the index date were excluded to prevent reverse causation.[24] We defined patients as users if they had at least one prescription for the candidate medication during the exposure period. To enable the testing of dose-response relationships we extracted data on the medication prescribed, number of packs / tablets and medication strength, and calculated defined daily doses (DDDs). The DDD system is a validated measure of drug consumption maintained by the World Health Organisation.[25] A single DDD is the average maintenance dose per day of a drug used for its main indication in adults (e.g. depression for citalopram). There was insufficient information to calculate DDDs for $0.4 \%$ of prescriptions, and implausible values were recorded in a further $2.0 \%$ (e.g. 1 tablet; $>50,000$ tablets). In these cases we assumed the most common DDD 
based on other prescriptions of that medication with complete information. We calculated the total number of DDDs received during follow-up, and categorised patients into those receiving zero, between 1 and 365 DDDs (less than one year's usage), and greater than 365 DDDs (more than one year's usage).

\section{Accounting for confounding factors}

We used data recorded in the CPRD during the exposure period to adjust for body mass index (normal [BMI under 25], overweight [BMI between 25 and 30], obese [BMI over 30]), smoking status (none, ex, current) and alcohol use (none, ex, current). We adjusted for differences in deprivation using the IMD score of the patient's home address. We accounted for the presence of ductal carcinoma in situ (DCIS; Read codes: B830.00, B825000, B830100) and each of the fifteen non-cancer related comorbidities within the Charlson index[26] during the exposure period (AIDS, cerebrovascular disease, chronic pulmonary disease, congestive heart disease, dementia, diabetes, diabetes with complications, hemiplegia, mild liver disease, moderate liver disease, myocardial infarction, peptic ulcer disease, peripheral vascular disease, renal disease, rheumatological disease) using a list of Read codes modified for use in the CPRD.[27] We also adjusted for the use of aspirin, statins, metformin, digoxin, oral contraceptives and hormone replacement therapy, as associations with breast cancer risk have been identified previously (Appendix 4).[8, 28, 29] We ignored confounders in the year prior to diagnoses to reduce reverse causation and overadjustment bias.[30]

\section{Statistical Analysis}

We calculated descriptive statistics and compared the demographics and clinical characteristics of the cases and controls. We used conditional logistic regression to estimate odds ratios (ORs) with 95\% confidence intervals ( $\mathrm{Cls}$ ) for the association between medication use and breast cancer. We ranked medications by their connectivity score and plotted this against their odds ratio to summarise our results. We used Spearman rank correlation coefficient to formally test for an association between the connectivity score and effect estimate. The matched design of the study appropriately accounted for the effect of age, general practice and year of diagnosis. We made additional adjustments for the presence of each comorbidity (yes/no), DCIS (yes/no), lifestyle factors (categorical), deprivation (quintiles) and other medication use (yes/no) using regression.

Although our main analysis was complete case, we also performed an additional sensitivity analysis using multiple imputation with chained equations (MICE) for smoking, alcohol consumption and BMI. The imputation used ordered logit models with age and deprivation, separately for cases and controls. Briefly, MICE is a simulation-based approach for handling missing data which leads to valid 
statistical inferences.[31] Sensitivity analyses were also conducted investigating the impact of excluding prescriptions in the two years prior to the index date (as opposed to one in the main analysis) and defining medication users as patients with at least three prescriptions (as opposed to one in the main analysis). Finally, we used Wald interaction tests to compare associations by age (dichotomised at 50 as this corresponds to the median menopausal age within the UK $[32,33]$ ), and estrogen receptor status (based on receipt of tamoxifen or aromatase inhibitors in the six months after breast cancer diagnosis), as risk factors have been shown to differ between these groups previously.[34, 35] 


\section{Results}

\section{Patient characteristics}

We identified 45,147 cases of breast cancer in our primary analysis with a median exposure period of 7.8 years (min: 3.0, max: 27.1). Overall, cases and controls were very similar in terms of their demographics, lifestyle and clinical history, although a slightly larger proportion of cases had previously been prescribed hormone replacement therapy ( $28.5 \%$ vs. $26.2 \%)$ and oral contraceptives (7.5\% vs. 6.6\%) (Table 1$)$.

\section{Association between medication use and breast cancer}

Overall, there was little convincing evidence that any of the medications included in our study substantially altered breast cancer risk (Table 2). The adjusted odds ratios (ORs) for ever use of azithromycin, rizatriptan, citalopram, rosiglitazone, sertraline, fluvastatin and budesonide were between 0.95 and 1.05. There was some evidence that verapamil (OR: 1.16; 95\% $\mathrm{Cl}: 0.99,1.37$ ) and bendroflumethiazide use (OR: 1.11; 95\% Cl: 1.06, 1.15) was associated with increased breast cancer risk, although effect estimates were small. For both these medications, our results were inconsistent with a dose-response relationship. The odds ratios for each of the confounders included in our model are provided in Appendix 5.

There was no clear relationship between the connectivity mapping score and the adjusted ORs for breast cancer risk (Spearman's correlation coefficient $=-0.067 ; p$-value $=0.855)$. The five medications with the largest connectivity scores (meloxicam, azithromycin, rizatriptan, citalopram and rosiglitazone), and three with the lowest connectivity scores (budesonide, fluvastatin and sertraline), had a small association with breast cancer, even among patients who received more than one year of treatment (Table 2, Figure 1). Furthermore, bendroflumethiazide was identified as a potentially cancer-reducing medication in the connectivity mapping, yet we found an $11 \%$ (OR: $1.11 ; 95 \% \mathrm{Cl}$ : $1.06,1.15)$ increase in breast cancer risk amongst users. Our findings were similar when restricting cases to those with a NCDR-confirmed breast cancer diagnosis, although the dose-response relationship for verapamil was no longer apparent. Furthermore, due to the smaller sample size, confidence intervals were noticeably wider in this analysis (Table 2, Appendix 6).

\section{Sensitivity and subgroup analysis}

In general, our conclusions were little altered in sensitivity analyses (Table 3). Similar associations were observed when prescriptions were excluded in the two years prior to diagnosis (rather than one), and when the definition of medication 'ever use' was based upon three or more prescriptions 
(rather than one). Using MICE to adjust for lifestyle factors (smoking, alcohol consumption, and obesity) resulted in similar estimates to the main, complete-case analysis. There was little evidence that any of the associations observed in our study differed according to menopausal or estrogenreceptor status (Appendix 7). 


\section{Discussion}

\section{Main Findings}

In this instance, our combined connectivity mapping and pharmacoepidemiological approach did not identify any additional medications which were substantially associated with breast cancer risk. Of the six medications expected to increase breast cancer risk, only verapamil had a noticeably higher risk, and this was relatively moderate in size (16\%). None of four medications predicted to reduce breast cancer had meaningfully lower risk. Indeed for one of these, bendroflumethiazide, users had an $11 \%$ increased breast cancer risk compared to non-users.

\section{Strengths and Limitations}

Our study is the first to combine connectivity mapping and pharmacoepidemiology to identify medications which may alter breast cancer. The utility and robustness of our connectivity mapping process have been tested in other drug discovery and repurposing research[36, 37], while the large collection of gene expression profiles for FDA approved medications facilitated a thorough analysis of potential connections with breast cancer risk. Our pharmacoepidemiology study is based on highquality and nationally representative CPRD data with long follow-up ( $>7.5$ years) for most patients.[18-20] We used prescribing data collected as part of routine clinical care, in many cases, several years before the onset of breast cancer which accurately reflects GP prescribing practices and negates the risk of recall bias.

Our study had several potential weakness. It is possible that the cell line models used during the connectivity mapping process do not always translate to human body. Furthermore, our connectivity mapping considered breast cancer as a single disease, potentially diluting important signals for specific breast cancer subtypes (e.g. triple negative). Future connectivity mapping which is stratified by breast cancer subtype may lead to different results. Our pharmacoepidemiology study is observational and hence open to confounding. Although we have controlled for several of the key determinants of breast cancer risk through the matched design and analysis (e.g. age, comorbidities and GP practice), some other risk factors, including breastfeeding and ethnicity, were not available.[38, 39] Our primary analysis is based on GP records of breast cancer diagnosis. However recent evidence suggests that over $96 \%$ of GP-recorded breast cancers can be validated using other data sources[22], and our conclusions were unchanged when restricting cases to those with an NCDR-confirmed diagnosis. 
We do not know if patients adhered to their prescribed medications, however our main conclusions were similar when restricting our analysis to patients who received multiple prescriptions (>365 DDDs), where non-compliance is less of a concern. Additionally, GP records do not contain data on over-the-counter medications which may have impaired our ability to accurately adjust for aspirin use (due to misclassification). Pharmacoepidemiology can only be used for commonly prescribed medications; other methodological approaches, such as cell or animal models, may be more suitable for rarer medications. Our study included a large number of medications which increased the probability of false-positive findings; therefore any 'statistically significant' results, specifically for bendroflumethiazide, should be interpreted with appropriate caution. Lastly, some of the medications explored in our analysis were rarely used within the UK general practice population. This may have led to lower power to detect differences in breast cancer risk between users and nonusers, particularly in our subgroup analyses.

\section{Comparisons with other research}

To our knowledge, this is the first study to combine connectivity mapping and pharmacoepidemiology to identify medications which alter breast cancer risk. Of the medications we considered, only rosiglitazone has been previously investigated in studies of breast cancer risk, with a recent meta-analysis reporting no evidence of an association, which was in keeping with our results.[40] None of the other medications included in our study have been investigated specifically, however studies of their drug class were common, and are potentially informative. In general, these were consistent with our study findings; for example, meta-analyses of nonsteroidal antiinflammatory drugs (meloxicam)[41], antibiotics (azithromycin)[42], selective serotonin reuptake inhibitors (citalopram, sertraline)[43] and statins (fluvastatin)[44] have all reported weak associations. Our finding of increased breast cancer risk among verapamil users is consistent with a recent meta-analysis of long-term calcium channel blocker users [45], while our estimate of $11 \%$ increased breast cancer risk among bendroflumethiazide users is similar to the results of two USbased studies of thiazide diuretics[46, 47], although a third found no association. [48] We found no studies investigating the association between rizatriptan or budesonide use (or their drug classes) and breast cancer risk.

\section{Implications}

Breast cancer places an important burden on population health, accounting for 520,000 deaths in Europe annually and $€ 15$ billion in costs. [2, 7] An improved understanding of the aetiology of breast cancer, or finding new cost-effective treatment options, could lead to better patient outcomes and financial savings. Although our combined connectivity mapping and pharmacoepidemiology 
approach theoretically offers an attractive way to achieve these goals, we did not to identify any new medications which were substantially associated with breast cancer risk.

There are several potential reasons why the findings from the connectivity mapping process did not translate into observable differences in breast cancer risk among medication users. Firstly, this could reflect the weaknesses of connectivity mapping, perhaps due to a reliance on cell cultures, and difficulty interpreting connectivity scores.[13] It may be that the doses prescribed in routine clinical practice are insufficiently large for the cancer causing or protective effects identified during the connectivity mapping to become apparent. Further laboratory-based in-vitro models could be used to pre-screen an initial list of medications derived from connectivity mapping, and exclude those where the required dose is unlikely to be achieved. Our study combined gene expression information from 68 distinct datasets. Although we aimed to remove potential 'batch effects', it could be that inter-sample heterogeneity has obfuscated true differences between normal and breast cancer cells. Secondly, it is possible that the true effects of medication use are masked by the limitations of an observational study design. For example, non-differential misclassification of drug exposure (due to medication non-adherence) would be expected to attenuate our estimates towards the null effect, while residual confounding could bias our estimates in either direction.[49] However, given the consistently small associations found across the diverse range of medications included in our study, it seems unlikely that these factors are solely driving our results. Additional work exploring the causes of our null results are required to refine this methodology for future studies.

Our finding of moderately increased breast cancer risk among verapamil and bendroflumethiazide users could require further investigation. These associations are broadly consistent with the findings from previous studies of their drug classes[45-47], and plausible biological mechanisms exist for their use to increase breast cancer risk. Specifically, calcium channel blockers are known to interfere with apoptosis which could facilitate the division of cells with a malignant potential[50,51], and thiazide diuretics may increase insulin resistance, an accepted risk factor for breast cancer.[52, 53]

\section{Conclusions}

In this instance, our combined connectivity mapping and pharmacoepidemiological approach did not identify any additional medications which were substantially associated with breast cancer risk. The cause of this is unknown, however it could be due to limitations in the connectivity mapping, such as implausible dosage requirements, or the pharmacoepidemiology, such as residual confounding. 
Additional work exploring the causes of our null results are required to refine this methodology for future studies. There was some evidence that verapamil and bendroflumethiazide users had slightly higher breast cancer risk, however further confirmatory studies are required. 


\section{Disclosures}

Acknowledgements: This study is based in part on data from the Clinical Practice Research Datalink obtained under licence from the UK Medicines and Healthcare products Regulatory Agency. However, the interpretation and conclusions contained in this study are those of the author/s alone. This work was funded by a project grant from Cancer Research-UK [C37316/A18225]

Conflict of interest statement: None to declare.

Authors' contributions: CC, LM, KM, SDZ and FL conceived the study. JB conducted the analysis and drafted the initial manuscript. All authors critically revised the article for intellectual content and approved the final manuscript. 


\section{References}

1. Office for National Statistics. Cancer Registration Statistics 2014, England. 2016 [cited 2016 11/10/2016]; Available from:

http://www.ons.gov.uk/peoplepopulationandcommunity/healthandsocialcare/conditionsan ddiseases/bulletins/cancerregistrationstatisticsengland/2014.

2. GLOBOCAN. Estimated Cancer Incidence, Mortaility and Prevelence Worldwide in 2012. 2012 03/11/2016].

3. Office for National Statistics. Cancer survival in England: Patients diagnosed between 2010 and 2014 and followed up to 2015. 2016 [cited 2016 11/10/16]; Available from:

http://www.ons.gov.uk/peoplepopulationandcommunity/healthandsocialcare/conditionsan ddiseases/bulletins/cancersurvivalinenglandadultsdiagnosed/2010and2014andfollowedupto 2015.

4. Blair, C.K., et al., Physical inactivity and risk of poor quality of life among elderly cancer survivors compared to women without cancer: the lowa Women's Health Study. Journal of Cancer Survivorship, 2016. 10(1): p. 103-112.

5. Klein, D., et al., Long-term quality of life after breast cancer: a French registry-based controlled study. Breast Cancer Research and Treatment, 2011. 129(1): p. 125-134.

6. Keetharuth, A., et al., Effects Of Cancer Treatment On Quality Of Life (ECTQOL): Final Results. 2014, Decision Support Unit, ScHARR: Sheffield.

7. Luengo-Fernandez, R., et al., Economic burden of cancer across the European Union: a population-based cost analysis. The Lancet Oncology. 14(12): p. 1165-1174.

8. Holmes, M.D. and W.Y. Chen, Hiding in plain view: the potential for commonly used drugs to reduce breast cancer mortality. Breast Cancer Research, 2012. 14(2): p. 1-9.

9. Ashburn, T.T. and K.B. Thor, Drug repositioning: identifying and developing new uses for existing drugs. Nat Rev Drug Discov, 2004. 3(8): p. 673-83.

10. Burn, J., et al., Long-term effect of aspirin on cancer risk in carriers of hereditary colorectal cancer: an analysis from the CAPP2 randomised controlled trial. The Lancet. 378(9809): $p$. 2081-2087.

11. Beral, V., Breast cancer and hormone-replacement therapy in the Million Women Study. Lancet, 2003. 362(9382): p. 419-27.

12. Martin, R.M., et al., What was the immediate impact on population health of the recent fall in hormone replacement therapy prescribing in England? Ecological study. J Public Health (Oxf), 2010. 32(4): p. 555-64.

13. Lamb, J., Innovation - The Connectivity Map: a new tool for biomedical research. Nature Reviews Cancer, 2007. 7(1): p. 54-60.

14. Lamb, J., et al., The connectivity map: Using gene-expression signatures to connect small molecules, genes, and disease. Science, 2006. 313(5795): p. 1929-1935.

15. Sirota, M., et al., Discovery and preclinical validation of drug indications using compendia of public gene expression data. Sci Transl Med, 2011. 3(96): p. 96ra77.

16. Avorn , J., In Defense of Pharmacoepidemiology - Embracing the Yin and Yang of Drug Research. New England Journal of Medicine, 2007. 357(22): p. 2219-2221.

17. Thillaiyampalam, G., et al., An integrated meta-analysis approach to identifying medications with potential to alter breast cancer risk through connectivity mapping BMC Bioinformatics, Under Review.

18. Herrett, E., et al., Data Resource Profile: Clinical Practice Research Datalink (CPRD). Int J Epidemiol, 2015. 44(3): p. 827-36.

19. Herrett, E., et al., Validation and validity of diagnoses in the General Practice Research Database: a systematic review. Br J Clin Pharmacol, 2010. 69(1): p. 4-14.

20. Jick, H., S.S. Jick, and L.E. Derby, Validation of information recorded on general practitioner based computerised data resource in the United Kingdom. Bmj, 1991. 302(6779): p. 766-8. 
21. Network, N.C.I. National Cancer Data Repository. 2016 [cited 2016 22/09/2016]; Available from:

http://www.ncin.org.uk/collecting and using data/national cancer data repository/.

22. Boggon, R., et al., Cancer recording and mortality in the General Practice Research Database and linked cancer registries. Pharmacoepidemiol Drug Saf, 2013. 22(2): p. 168-75.

23. Suissa, S., et al., Time-window bias in case-control studies: statins and lung cancer. Epidemiology, 2011. 22(2): p. 228-31.

24. Tamim, H., A.A. Monfared, and J. LeLorier, Application of lag-time into exposure definitions to control for protopathic bias. Pharmacoepidemiol Drug Saf, 2007. 16(3): p. 250-8.

25. World Health Organization. The Anatomical Therapeutic Chemical Classification System With Defined Daily Doses. 2016 08/11/2016]; Available from:

http://www.who.int/classifications/atcddd/en/.

26. Charlson, M.E., et al., A new method of classifying prognostic comorbidity in longitudinal studies: development and validation. J Chronic Dis, 1987. 40(5): p. 373-83.

27. Khan, N.F., et al., Adaptation and validation of the Charlson Index for Read/OXMIS coded databases. BMC Fam Pract, 2010. 11: p. 1.

28. Nelson, H.D., et al., Postmenopausal hormone replacement therapy - Scientific review. JamaJournal of the American Medical Association, 2002. 288(7): p. 872-881.

29. Gierisch, J.M., et al., Oral Contraceptive Use and Risk of Breast, Cervical, Colorectal, and Endometrial Cancers: A Systematic Review. Cancer Epidemiology Biomarkers \& Prevention, 2013. 22(11): p. 1931-1943.

30. Schisterman, E.F., S.R. Cole, and R.W. Platt, Overadjustment Bias and Unnecessary Adjustment in Epidemiologic Studies. Epidemiology (Cambridge, Mass.), 2009. 20(4): p. 488495.

31. White, I.R., P. Royston, and A.M. Wood, Multiple imputation using chained equations: Issues and guidance for practice. Stat Med, 2011. 30(4): p. 377-99.

32. Pokoradi, A.J., L. Iversen, and P.C. Hannaford, Factors associated with age of onset and type of menopause in a cohort of UK women. American Journal of Obstetrics and Gynecology, 2011. 205(1): p. 13.

33. Mishra, G., R. Hardy, and D. Kuh, Are the effects of risk factors for timing of menopause modified by age? Results from a British birth cohort study. Menopause, 2007. 14(4): p. 71724.

34. Hirose, K., et al., A Large-Scale, Hospital-Based Case-Central Study Of Risk-Factors Of BreastCancer According To Menopausal Status. Japanese Journal of Cancer Research, 1995. 86(2): p. 146-154.

35. Colditz, G.A., et al., Risk Factors for Breast Cancer According to Estrogen and Progesterone Receptor Status. Journal of the National Cancer Institute, 2004. 96(3): p. 218-228.

36. Malcomson, B., et al., Connectivity mapping (ssCMap) to predict A20-inducing drugs and their antiinflammatory action in cystic fibrosis. Proc Natl Acad Sci U S A, 2016. 113(26): p. E3725-34.

37. Wen, Q., et al., KRAS mutant colorectal cancer gene signatures identified angiotensin II receptor blockers as potential therapies. Oncotarget, 2017. 8(2): p. 3206-3225.

38. Islami, F., et al., Breastfeeding and breast cancer risk by receptor status-a systematic review and meta-analysis. Annals of Oncology, 2015. 26(12): p. 2398-2407.

39. Vainshtein, J., Disparities in breast cancer incidence across racial/ethnic strata and socioeconomic status: a systematic review. J Natl Med Assoc, 2008. 100(7): p. 833-9.

40. Monami, M., I. Dicembrini, and E. Mannucci, Thiazolidinediones and cancer: results of a meta-analysis of randomized clinical trials. Acta Diabetol, 2014. 51(1): p. 91-101.

41. Khuder, S.A. and A.B. Mutgi, Breast cancer and NSAID use: a meta-analysis. Br J Cancer, 2001. 84(9): p. 1188-92. 
42. Sergentanis, T.N., F. Zagouri, and G.C. Zografos, Is antibiotic use a risk factor for breast cancer? A meta-analysis. Pharmacoepidemiol Drug Saf, 2010. 19(11): p. 1101-7.

43. Eom, C.S., S.M. Park, and K.H. Cho, Use of antidepressants and the risk of breast cancer: a meta-analysis. Breast Cancer Res Treat, 2012. 136(3): p. 635-45.

44. Wu, Q.J., et al., Statin use and breast cancer survival and risk: a systematic review and metaanalysis. Oncotarget, 2015. 6(40): p. 42988-3004.

45. Li, W., et al., Calcium Channel Blockers and Risk of Breast Cancer: A Meta-Analysis of 17 Observational Studies. PLoS ONE, 2014. 9(9): p. e105801.

46. Largent, J.A., et al., Hypertension, antihypertensive medication use, and breast cancer risk in the California Teachers Study cohort. Cancer Causes Control, 2010. 21(10): p. 1615-24.

47. Li, C.I., et al., Relation between use of antihypertensive medications and risk of breast carcinoma among women ages 65-79 years. Cancer, 2003. 98(7): p. 1504-13.

48. Li, C.I., et al., Use of anti-hypertensive medications and breast cancer risk among women 5574 years of age. JAMA internal medicine, 2013. 173(17): p. 1629-1637.

49. Rothman, K.J., S. Greenland, and T.L. Lash. Modern epidemiology. 2008; Available from: http://public.eblib.com/choice/publicfullrecord.aspx?p=2032120.

50. Carson, D.A. and J.M. Ribeiro, Apoptosis and disease. Lancet, 1993. 341(8855): p. 1251-4.

51. Pahor, M., et al., Do calcium channel blockers increase the risk of cancer? Am J Hypertens, 1996. 9(7): p. 695-9.

52. Andersson, O.K., T. Gudbrandsson, and K. Jamerson, Metabolic adverse effects of thiazide diuretics: the importance of normokalaemia. J Intern Med Suppl, 1991. 735: p. 89-96.

53. Muti, P., et al., Markers of insulin resistance and sex steroid hormone activity in relation to breast cancer risk: a prospective analysis of abdominal adiposity, sebum production, and hirsutism (Italy). Cancer Causes Control, 2000. 11(8): p. 721-30. 


\section{Tables}

Table 1: Patient characteristics, NCDR and GP recorded cases

\begin{tabular}{|c|c|c|}
\hline & Cases & Controls \\
\hline Count & 45,147 & 45,147 \\
\hline Median Exposure Years (Min, Max) & $7.8(3.0,27.1)$ & $7.8(3.0,27.1)$ \\
\hline \multicolumn{3}{|l|}{ Year of Diagnosis } \\
\hline $1995-2002$ & $10,191(22.6 \%)$ & $10,165(22.5 \%)$ \\
\hline 2003-2006 & $11,474(25.4 \%)$ & $11,489(25.4 \%)$ \\
\hline $2007-2010$ & $23,482(52.0 \%)$ & $23,493(52.0 \%)$ \\
\hline Mean Age (SD) & $62.8(14.1)$ & $62.8(14.1)$ \\
\hline $0-39$ & $1,751(3.9 \%)$ & $1,751(3.9 \%)$ \\
\hline $40-59$ & $17,643(39.1 \%)$ & $17,643(39.1 \%)$ \\
\hline $60-79$ & 19,307 (42.8\%) & $19,307(42.8 \%)$ \\
\hline $80+$ & $6,446(14.3 \%)$ & $6,446(14.3 \%)$ \\
\hline \multicolumn{3}{|l|}{ Smoking } \\
\hline No & $28,369(66.5 \%)$ & $28,157(66.8 \%)$ \\
\hline Ex & 4,482 (10.5\%) & $4,254(10.1 \%)$ \\
\hline Yes & $9,817(23.0 \%)$ & $9,744(23.1 \%)$ \\
\hline Missing & 2,479 & 2,992 \\
\hline \multicolumn{3}{|l|}{ Alcohol } \\
\hline No & $8,271(21.2 \%)$ & $8,742(22.8 \%)$ \\
\hline Ex & $250(0.6 \%)$ & $248(0.6 \%)$ \\
\hline Yes & $30,463(78.1 \%)$ & $29,379(76.6 \%)$ \\
\hline Missing & 6,163 & 6,778 \\
\hline \multicolumn{3}{|l|}{ Obesity } \\
\hline Normal & $19,572(49.8 \%)$ & $19,643(50.7 \%)$ \\
\hline Overweight & $12,448(31.7 \%)$ & $12,187(31.4 \%)$ \\
\hline Obese & $7,268(18.5 \%)$ & 6,921 (17.9\%) \\
\hline Missing & 5,859 & 6,396 \\
\hline \multicolumn{3}{|l|}{ Deprivation Quintile } \\
\hline 1 (Least Deprived) & 10,665 (23.6\%) & $10,238(22.7 \%)$ \\
\hline 2 & $9,573(21.2 \%)$ & $9,215(20.4 \%)$ \\
\hline 3 & $8,956(19.8 \%)$ & $9,022(20.0 \%)$ \\
\hline 4 & 8,637 (19.1\%) & $8,857(19.6 \%)$ \\
\hline 5 (Most Deprived) & $7,316(16.2 \%)$ & $7,815(17.3 \%)$ \\
\hline Mean Charlson Score (SD) & $0.61(1.08)$ & $0.60(1.05)$ \\
\hline Any Comorbidity ${ }^{\dagger}$ & $15,024(33.3 \%)$ & $14,959(33.1 \%)$ \\
\hline Chronic pulmonary disease & 7,557 (16.7\%) & $7,542(16.7 \%)$ \\
\hline Diabetes & $2,924(6.5 \%)$ & $2,727(6.0 \%)$ \\
\hline Renal disease & $2,355(5.2 \%)$ & $2,312(5.1 \%)$ \\
\hline Rheumatological disease & $1,531(3.4 \%)$ & $1,831(4.1 \%)$ \\
\hline Cerebrovascular disease & $1,618(3.6 \%)$ & $1,651(3.7 \%)$ \\
\hline \multicolumn{3}{|l|}{ Other Medication Use } \\
\hline Hormone Replacement Therapy & $12,846(28.5 \%)$ & $11,816(26.2 \%)$ \\
\hline Statin & $7,820(17.3 \%)$ & $7,807(17.3 \%)$ \\
\hline Aspirin & 7,617 (16.9\%) & $7,613(16.9 \%)$ \\
\hline Oral Contraceptive & $3,396(7.5 \%)$ & $2,991(6.6 \%)$ \\
\hline Metformin & $1,773(3.9 \%)$ & $1,655(3.7 \%)$ \\
\hline Digoxin & $1,084(2.4 \%)$ & $911(2.0 \%)$ \\
\hline
\end{tabular}

† For brevity only the 5 most common comorbidities are listed. The full analysis included AIDS, cerebrovascular disease, chronic pulmonary disease, congestive heart disease, dementia, diabetes, diabetes with complications, ductal carcinoma in situ, hemiplegia, mild liver disease, moderate liver disease, myocardial infarction, peptic ulcer disease, peripheral vascular disease, renal disease, rheumatological disease. 
Table 2: Breast cancer risk by level of medication use

\begin{tabular}{|c|c|c|c|c|c|}
\hline \multirow[b]{2}{*}{ Substance } & \multicolumn{4}{|c|}{ NCDR and GP recorded cases } & \multirow{2}{*}{$\begin{array}{c}\text { NCDR cases } \\
\text { Adjusted OR } \\
(95 \% \mathrm{Cl})\end{array}$} \\
\hline & Cases & Controls & $\begin{array}{l}\text { Unadjusted OR } \\
(95 \% \mathrm{Cl})\end{array}$ & $\begin{array}{c}\text { Adjusted OR } \\
(95 \% \mathrm{CI})^{\dagger}\end{array}$ & \\
\hline \multicolumn{6}{|c|}{ Meloxicam (Connectivity Score [CS] = 5.6) } \\
\hline Never & $43,543(96.4 \%)$ & $43,613(96.6 \%)$ & Ref & Ref & Ref \\
\hline Ever & $1,604(3.6 \%)$ & $1,534(3.4 \%)$ & $1.05(0.98,1.13)$ & $1.04(0.96,1.14)$ & $1.12(0.96,1.29)$ \\
\hline 1-365 DDDs $\ddagger$ & $1,347(3.0 \%)$ & $1,307(2.9 \%)$ & $1.04(0.96,1.12)$ & $1.01(0.92,1.11)$ & $1.09(0.92,1.28)$ \\
\hline$>365$ DDDs & $257(0.6 \%)$ & $227(0.5 \%)$ & $1.14(0.95,1.36)$ & $1.22(1.00,1.49)$ & $1.27(0.90,1.80)$ \\
\hline \multicolumn{6}{|c|}{ Azithromycin (CS=4.7) } \\
\hline Never & $44,813(99.3 \%)$ & $44,782(99.2 \%)$ & Ref & Ref & Ref \\
\hline Ever & $334(0.7 \%)$ & $365(0.8 \%)$ & $0.91(0.78,1.06)$ & $0.93(0.78,1.11)$ & $1.04(0.75,1.44)$ \\
\hline 1-365 DDDs & $328(0.7 \%)$ & $359(0.8 \%)$ & $0.91(0.78,1.06)$ & $0.93(0.78,1.11)$ & $1.03(0.74,1.42)$ \\
\hline$>365 \mathrm{DDDs}$ & $6(0.0 \%)$ & $6(0.0 \%)$ & N/A & N/A & N/A \\
\hline \multicolumn{6}{|c|}{ Rizatriptan $(C S=4.6)$} \\
\hline Never & 44,905 (99.5\%) & 44,904 (99.5\%) & Ref & Ref & Ref \\
\hline Ever & $242(0.5 \%)$ & $243(0.5 \%)$ & $1.00(0.83,1.19)$ & $1.11(0.90,1.36)$ & $1.12(0.79,1.59)$ \\
\hline 1-365 DDDs & $228(0.5 \%)$ & $230(0.5 \%)$ & $0.99(0.82,1.19)$ & $1.07(0.86,1.32)$ & $1.14(0.80,1.63)$ \\
\hline$>365$ DDDs & $14(0.0 \%)$ & $13(0.0 \%)$ & $\mathrm{N} / \mathrm{A}$ & N/A & $\mathrm{N} / \mathrm{A}$ \\
\hline \multicolumn{6}{|c|}{ Citalopram (CS=4.3) } \\
\hline Never & $41,293(91.5 \%)$ & $41,348(91.6 \%)$ & Ref & Ref & Ref \\
\hline Ever & $3,854(8.5 \%)$ & $3,799(8.4 \%)$ & $1.02(0.97,1.07)$ & $1.01(0.96,1.07)$ & $1.06(0.96,1.18)$ \\
\hline 1-365 DDDs & $2,648(5.9 \%)$ & $2,612(5.8 \%)$ & $1.02(0.96,1.08)$ & $1.00(0.94,1.07)$ & $1.04(0.92,1.17)$ \\
\hline$>365$ DDDs & $1,206(2.7 \%)$ & $1,187(2.6 \%)$ & $1.02(0.94,1.11)$ & $1.03(0.94,1.13)$ & $1.14(0.94,1.38)$ \\
\hline \multicolumn{6}{|c|}{ Rosiglitazone (CS=3.8) } \\
\hline Never & 44,893 (99.4\%) & 44,889 (99.4\%) & Ref & Ref & Ref \\
\hline Ever & $254(0.6 \%)$ & $258(0.6 \%)$ & $0.98(0.83,1.17)$ & $1.00(0.81,1.22)$ & $0.88(0.62,1.26)$ \\
\hline 1-365 DDDs & $112(0.2 \%)$ & $102(0.2 \%)$ & $1.10(0.84,1.44)$ & $1.03(0.76,1.41)$ & $1.11(0.67,1.82)$ \\
\hline$>365$ DDDs & $142(0.3 \%)$ & $156(0.3 \%)$ & $0.91(0.72,1.14)$ & $0.97(0.75,1.26)$ & $0.73(0.46,1.16)$ \\
\hline \multicolumn{6}{|c|}{ Verapamil $(\mathrm{CS}=3.6)$} \\
\hline Never & 44,671 (98.9\%) & 44,753 (99.1\%) & Ref & Ref & Ref \\
\hline Ever & 476 (1.1\%) & 394 (0.9\%) & $1.21(1.06,1.39)$ & $1.16(0.99,1.37)$ & $1.11(0.86,1.44)$ \\
\hline 1-365 DDDs & $211(0.5 \%)$ & $179(0.4 \%)$ & $1.18(0.97,1.44)$ & $1.08(0.85,1.37)$ & $1.17(0.81,1.70)$ \\
\hline$>365$ DDDs & $265(0.6 \%)$ & $215(0.5 \%)$ & $1.24(1.03,1.49)$ & $1.24(1.00,1.54)$ & $1.06(0.74,1.52)$ \\
\hline \multicolumn{6}{|c|}{ Bendroflumethiazide (CS=-4.6) } \\
\hline Never & $35,783(79.3 \%)$ & 36,347 (80.5\%) & Ref & Ref & Ref \\
\hline Ever & $9,364(20.7 \%)$ & 8,800 (19.5\%) & $1.09(1.06,1.13)$ & $1.11(1.06,1.15)$ & $1.10(1.03,1.18)$ \\
\hline 1-365 DDDs & $2,925(6.5 \%)$ & $2,795(6.2 \%)$ & $1.07(1.01,1.13)$ & $1.07(1.01,1.15)$ & $1.09(0.98,1.21)$ \\
\hline$>365$ DDDs & $6,439(14.3 \%)$ & 6,005 (13.3\%) & $1.10(1.06,1.15)$ & $1.12(1.07,1.18)$ & $1.11(1.02,1.20)$ \\
\hline \multicolumn{6}{|c|}{ Sertraline $(C S=-4.6)$} \\
\hline Never & $43,784(97.0 \%)$ & 43,790 (97.0\%) & Ref & Ref & Ref \\
\hline Ever & 1,363 (3.0\%) & 1,357 (3.0\%) & $1.00(0.93,1.09)$ & $1.01(0.92,1.11)$ & $1.03(0.88,1.22)$ \\
\hline 1-365 DDDs & $906(2.0 \%)$ & $899(2.0 \%)$ & $1.01(0.92,1.11)$ & $1.03(0.92,1.14)$ & $1.01(0.83,1.23)$ \\
\hline$>365$ DDDs & 457 (1.0\%) & $458(1.0 \%)$ & $1.00(0.88,1.14)$ & $0.98(0.84,1.14)$ & $1.08(0.82,1.43)$ \\
\hline \multicolumn{6}{|c|}{ Fluvastatin $(C S=-5.0)$} \\
\hline Never & $44,944(99.6 \%)$ & 44,945 (99.6\%) & Ref & Ref & Ref \\
\hline Ever & $203(0.4 \%)$ & $202(0.4 \%)$ & $1.01(0.82,1.23)$ & $0.98(0.78,1.23)$ & $1.17(0.79,1.73)$ \\
\hline 1-365 DDDs & $134(0.3 \%)$ & $125(0.3 \%)$ & $1.07(0.84,1.38)$ & $0.99(0.75,1.32)$ & $1.19(0.74,1.92)$ \\
\hline$>365 \mathrm{DDDs}$ & $69(0.2 \%)$ & $77(0.2 \%)$ & $0.90(0.65,1.24)$ & $0.95(0.65,1.39)$ & $1.12(0.56,2.23)$ \\
\hline \multicolumn{6}{|c|}{ Budesonide (CS=-7.5) } \\
\hline Never & $43,578(96.5 \%)$ & 43,535 (96.4\%) & Ref & Ref & Ref \\
\hline Ever & $1,569(3.5 \%)$ & $1,612(3.6 \%)$ & $0.97(0.90,1.04)$ & $0.96(0.88,1.04)$ & $0.90(0.77,1.06)$ \\
\hline 1-365 DDDs & $1,041(2.3 \%)$ & $1,042(2.3 \%)$ & $1.00(0.91,1.09)$ & $0.97(0.87,1.07)$ & $0.84(0.70,1.01)$ \\
\hline$>365$ DDDs & $528(1.2 \%)$ & $570(1.3 \%)$ & $0.92(0.82,1.04)$ & $0.93(0.81,1.07)$ & $1.08(0.82,1.42)$ \\
\hline
\end{tabular}

${ }^{\dagger}$ Adjusted for comorbidities (AIDS, cerebrovascular disease, chronic pulmonary disease, congestive heart disease, dementia, diabetes, diabetes with complications, ductal carcinoma in situ, hemiplegia, mild liver disease, moderate liver disease, myocardial infarction, peptic ulcer disease, peripheral vascular disease, renal disease, rheumatological disease), confounder medications (aspirin, digoxin, hormone replacement therapy, metformin, oral contraceptive, statin), deprivation, smoking status, alcohol consumption and obesity. Additionally conditioned on age, GP practice and year of diagnosis

FDefined daily dose 
Table 3: Sensitivity analysis of breast cancer risk by ever medication use, NCDR and GP recorded cases

\begin{tabular}{|c|c|c|c|c|}
\hline & Cases & Controls & $\begin{array}{c}\text { Unadjusted OR } \\
(95 \% \mathrm{Cl})\end{array}$ & $\begin{array}{c}\text { Adjusted OR } \\
(95 \% \mathrm{CI})^{\dagger}\end{array}$ \\
\hline \multicolumn{5}{|l|}{ Meloxicam } \\
\hline 2-year exposure lag & $1,427(3.2 \%)$ & $1,361(3.0 \%)$ & $1.05(0.97,1.14)$ & $1.04(0.95,1.14)$ \\
\hline Ever use $\geq 3$ prescriptions & $680(1.5 \%)$ & $665(1.5 \%)$ & $1.02(0.92,1.14)$ & $1.07(0.94,1.21)$ \\
\hline MI lifestyle adjusted ${ }^{\ddagger}$ & $1,604(3.6 \%)$ & $1,534(3.4 \%)$ & $1.05(0.98,1.13)$ & $1.06(0.98,1.14)$ \\
\hline \multicolumn{5}{|l|}{ Azithromycin } \\
\hline 2-year exposure lag & $289(0.6 \%)$ & $310(0.7 \%)$ & $0.93(0.79,1.09)$ & $0.94(0.78,1.14)$ \\
\hline Ever use $\geq 3$ prescriptions & $40(0.1 \%)$ & $47(0.1 \%)$ & $0.85(0.56,1.30)$ & $0.92(0.57,1.49)$ \\
\hline MI lifestyle adjusted & $334(0.7 \%)$ & $365(0.8 \%)$ & $0.91(0.78,1.06)$ & $0.90(0.77,1.05)$ \\
\hline \multicolumn{5}{|l|}{ Rizatriptan } \\
\hline 2-year exposure lag & $211(0.5 \%)$ & $208(0.5 \%)$ & $1.01(0.84,1.23)$ & $1.09(0.88,1.36)$ \\
\hline Ever use $\geq 3$ prescriptions & $108(0.2 \%)$ & $131(0.3 \%)$ & $0.82(0.64,1.06)$ & $0.84(0.63,1.12)$ \\
\hline MI lifestyle adjusted & $242(0.5 \%)$ & $243(0.5 \%)$ & $1.00(0.83,1.19)$ & $1.00(0.83,1.20)$ \\
\hline \multicolumn{5}{|l|}{ Citalopram } \\
\hline 2-year exposure lag & $3,282(7.3 \%)$ & $3,253(7.2 \%)$ & $1.01(0.96,1.06)$ & $1.01(0.95,1.08)$ \\
\hline Ever use $\geq 3$ prescriptions & $2,556(5.7 \%)$ & 2,469 (5.5\%) & $1.04(0.98,1.10)$ & $1.05(0.98,1.12)$ \\
\hline MI lifestyle adjusted & $3,854(8.5 \%)$ & $3,799(8.4 \%)$ & $1.02(0.97,1.07)$ & $1.01(0.96,1.06)$ \\
\hline \multicolumn{5}{|l|}{ Rosiglitazone } \\
\hline 2-year exposure lag & $218(0.5 \%)$ & $223(0.5 \%)$ & $0.98(0.81,1.18)$ & $1.01(0.81,1.25)$ \\
\hline Ever use $\geq 3$ prescriptions & $215(0.5 \%)$ & $226(0.5 \%)$ & $0.95(0.79,1.15)$ & $0.95(0.76,1.18)$ \\
\hline MI lifestyle adjusted & $254(0.6 \%)$ & $258(0.6 \%)$ & $0.98(0.83,1.17)$ & $0.92(0.76,1.10)$ \\
\hline \multicolumn{5}{|l|}{ Verapamil } \\
\hline 2-year exposure lag & $427(0.9 \%)$ & $372(0.8 \%)$ & $1.15(1.00,1.32)$ & $1.14(0.97,1.35)$ \\
\hline Ever use $\geq 3$ prescriptions & $372(0.8 \%)$ & $307(0.7 \%)$ & $1.22(1.04,1.42)$ & $1.19(0.99,1.43)$ \\
\hline MI lifestyle adjusted & 476 (1.1\%) & 394 (0.9\%) & $1.21(1.06,1.39)$ & $1.19(1.04,1.36)$ \\
\hline \multicolumn{5}{|l|}{ Bendroflumethiazide } \\
\hline 2-year exposure lag & $8,647(19.2 \%)$ & 8,087 (17.9\%) & $1.10(1.06,1.14)$ & $1.11(1.07,1.16)$ \\
\hline Ever use $\geq 3$ prescriptions & $7,718(17.1 \%)$ & $7,204(16.0 \%)$ & $1.10(1.06,1.14)$ & $1.11(1.06,1.16)$ \\
\hline MI lifestyle adjusted & $9,364(20.7 \%)$ & $8,800(19.5 \%)$ & $1.09(1.06,1.13)$ & $1.09(1.05,1.13)$ \\
\hline \multicolumn{5}{|l|}{ Sertraline } \\
\hline 2-year exposure lag & $1,191(2.6 \%)$ & $1,179(2.6 \%)$ & $1.01(0.93,1.10)$ & $1.02(0.92,1.12)$ \\
\hline Ever use $\geq 3$ prescriptions & $826(1.8 \%)$ & $808(1.8 \%)$ & $1.02(0.93,1.13)$ & $1.01(0.90,1.13)$ \\
\hline MI lifestyle adjusted & $1,363(3.0 \%)$ & $1,357(3.0 \%)$ & $1.00(0.93,1.09)$ & $1.00(0.92,1.08)$ \\
\hline \multicolumn{5}{|l|}{ Fluvastatin } \\
\hline 2-year exposure lag & $185(0.4 \%)$ & $188(0.4 \%)$ & $0.98(0.80,1.21)$ & $0.95(0.75,1.20)$ \\
\hline Ever use $\geq 3$ prescriptions & $141(0.3 \%)$ & $155(0.3 \%)$ & $0.91(0.72,1.14)$ & $0.92(0.70,1.21)$ \\
\hline MI lifestyle adjusted & $203(0.4 \%)$ & $202(0.4 \%)$ & $1.01(0.82,1.23)$ & $1.02(0.83,1.25)$ \\
\hline \multicolumn{5}{|l|}{ Budesonide } \\
\hline 2-year exposure lag & $1,390(3.1 \%)$ & $1,449(3.2 \%)$ & $0.96(0.89,1.03)$ & $0.94(0.86,1.03)$ \\
\hline Ever use $\geq 3$ prescriptions & $997(2.2 \%)$ & $984(2.2 \%)$ & $1.01(0.93,1.11)$ & $0.99(0.89,1.10)$ \\
\hline MI lifestyle adjusted & $1,569(3.5 \%)$ & $1,612(3.6 \%)$ & $0.97(0.90,1.04)$ & $0.96(0.89,1.03)$ \\
\hline
\end{tabular}

${ }^{\dagger}$ Adjusted for comorbidities (AIDS, cerebrovascular disease, chronic pulmonary disease, congestive heart disease, dementia, diabetes, diabetes with complications, ductal carcinoma in situ, hemiplegia, mild liver disease, moderate liver disease, myocardial infarction, peptic ulcer disease, peripheral vascular disease, renal disease, rheumatological disease), confounder medications (aspirin, digoxin, hormone replacement therapy, metformin, oral contraceptive, statin), deprivation, smoking status, alcohol consumption and obesity. Additionally conditioned on age, GP practice and year of diagnosis

¥Multiple imputation with chained equations for smoking, alcohol consumption and obesity with age and deprivation used in the imputation, separately for cases and controls, using chained ordered logit models 


\section{Figure Legends}

Figure 1: Breast cancer risk by ever medication use, NCDR and GP recorded cases. Odds ratio for each medication, ordered by decreasing connectivity score. Circle represents odds ratios, vertical lines represent the $95 \%$ confidence intervals. 


\section{Figures}

Figure 1: Breast cancer risk by ever medication use, NCDR and GP recorded cases ${ }^{\dagger}$

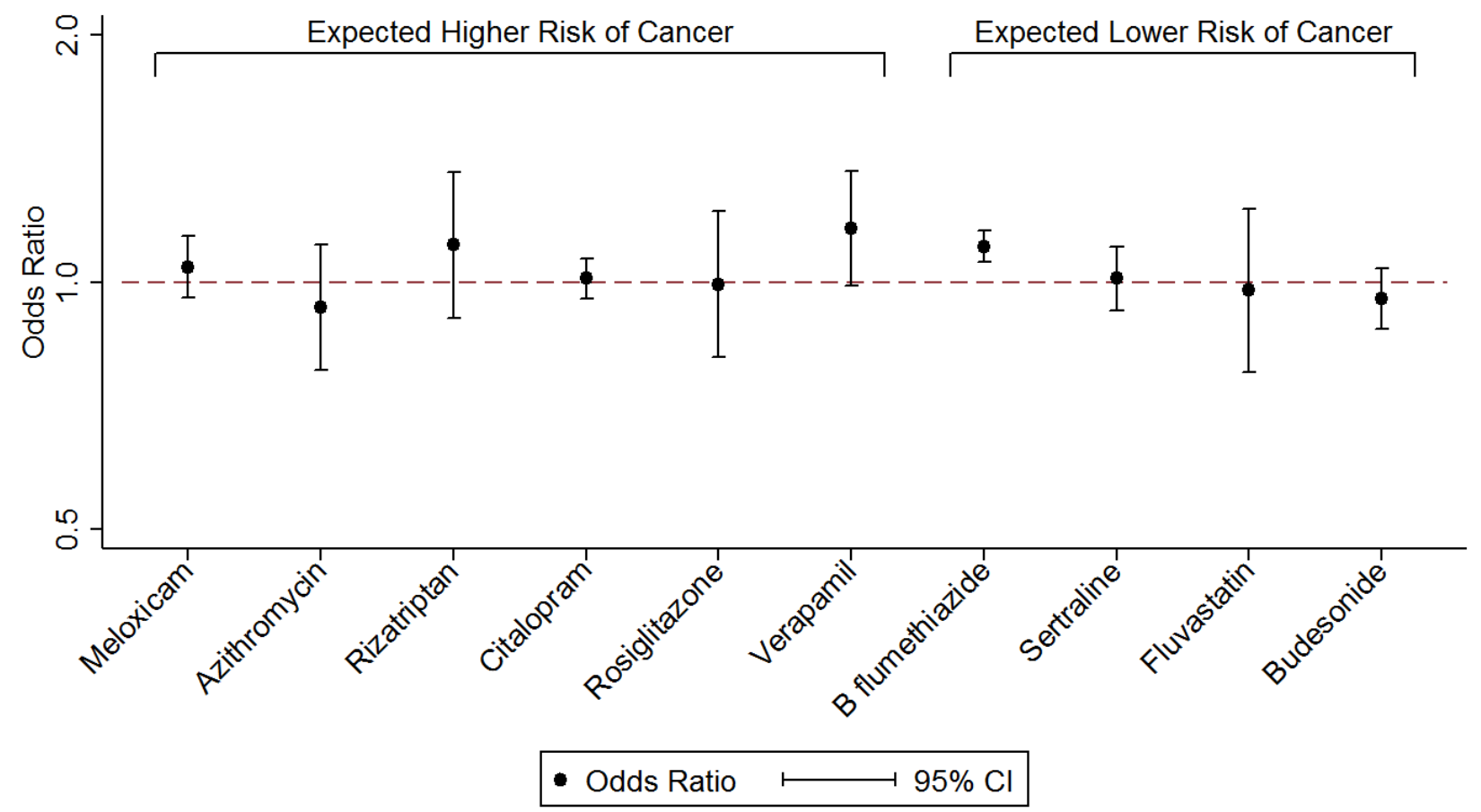

${ }^{\dagger}$ Adjusted for comorbidities (AIDS, cerebrovascular disease, chronic pulmonary disease, congestive heart disease, dementia, diabetes, diabetes with complications, ductal carcinoma in situ, hemiplegia, mild liver disease, moderate liver disease, myocardial infarction, peptic ulcer disease, peripheral vascular disease, renal disease, rheumatological disease), confounder medications (aspirin, digoxin, hormone replacement therapy, metformin, oral contraceptive, statin), deprivation, smoking status, alcohol consumption and obesity. Additionally conditioned on age, GP practice and year of diagnosis 


\section{Appendices}

\section{Appendix 1: Brief description of connectivity score derivation}

1. Selection of samples: Our search of two gene expression repositories (Gene Expression Omnibus and ArrayExpress) for 'breast cancer' resulted in 68 distinct datasets (7,530 eligible samples) across two groups:

a. Normal: Breast tissue samples from healthy individuals $(n=212)$

b. Tumour: Pre-treatment primary breast tumour samples $(n=7,318)$

2. Processing of gene expression data: The Affymetrix MAS5 algorithm was applied to generate an expression data matrix for each of the 68 datasets, and these were merged into a single file. Combining these heterogeneous datasets can lead to 'batch effects', so we used the ComBat correction method to remove these.

3. Differential expression analysis and filtering: We preformed differential expression analysis to identify differentially expressed genes across the tumour and normal groups. The statistical significance of any differential expression was assessed using the non-parametric two-sample Wilcoxon test. We used a p-value of $1 / 22277$ (the number of comparisons), to account for multiple testing. The genes that passed the statistical significance filter were further examined on their magnitude of differential expression to ensure they were also biologically significant. 415 gene probes were selected as both statistically and biologically significant, and served as the input to identify medications that can potentially alter breast cancer risk.

4. Gene signature creation: The 415 gene probes derived from step 3 could form a single gene signature for connectivity mapping. However, for technical reasons, we split these 415 gene probes into five equal length 83-gene (sub) signatures, and ran the connectivity mapping separately for each sub-signature. We used LINCS data, which includes 83,000 reference profiles from over 1,300 FDA approved medications, as the core reference database in connectivity mapping. Each sub gene signature was used as an input to calculate the connection score (which can be interpreted similarly to a $z$-score from a standard normal distribution) and $p$-value. These indicate the strength of the relationship between the input gene signature and medication. Therefore, a positive connectivity score indicates a medication with potential cancer-causing properties, whilst a negative score signifies a medication with potential cancer-preventing properties.

5. Connectivity mapping: For each input gene signature, connectivity mapping analysis returns its connection score and associated $\mathrm{p}$-value for all medications in the core database. We used a pvalue of 1/1349 (number of FDA approved medications) to guard against multiple testing. We selected only the 67 medications which were statistically significantly associated with at least four out of the five gene signatures described above. As these medications were connected to all (or most) of the breast cancer signatures, we could have confidence that they might affect breast cancer risk.

Further details on the connectivity mapping process are available upon request. 


\section{Appendix 2: Medications excluded from the analysis}

\begin{tabular}{ll}
\hline Exclusion Reason & Medication \\
\hline Limited primary care use & Acepromazine, Auranofin, Azathioprine, Bacitracin, Butalbital, Cefotiam Hydrochloride, Desipramine \\
& Hydrochloride, Diloxanide Furoate, Doxylamine Succinate, Entecavir, Epinephrine, Flecainide Acetate, \\
& Isocarboxazid, Menadione, Metaraminol Bitartrate, Milnacipran, Minoxidil, Phenindione, Quinacrine, \\
& Reserpine, Sulfacetamide, Sulfafurazole, Tadalafil, Timolol, Triprolidine Hydrochloride, Tyloxapol, Valproic-Acid, \\
& Zalcitabine \\
Cancer treatment & Aminolevulinic Acid, Azacitidine, Chlorambucil, Cladribine, Cytarabine, Dexrazoxane, Doxorubicin, Etoposide, \\
& Gefitinib, Gemcitabine, Gemcitabine Hydrochloride, Glutamic Acid, Methotrexate, Pazopanib, Raltitrexed, \\
Topical / nasal & Teniposide, Topotecan Hcl, Trametinib, Tretinoin, Trihydrate, Vorinostat \\
Available over the counter & Beclomethasone, Bromidine, Clotrimazole, Levocabastine, Mometasone Furoate \\
Known breast cancer association & Gamma-Linolenic Acid, Ibuprofen \\
\hline
\end{tabular}


Appendix 3: List of drug names for each exposure compound

\begin{tabular}{ll}
\hline Substance Name & Medication \\
\hline Meloxicam & Meloxicam \\
Azithromycin & Azithromycin, Azyter, Zedbac, Zithromax \\
Rizatriptan & Rizatriptan, Maxalt \\
Citalopram & Citalopram, Cipralex, Cipramil, Escitalopram \\
Rosiglitazone & Rosiglitazone \\
Verapamil & Verapamil, Securon, Univer, Vera-Til, Verapress, Vertab, Zolvera \\
Bendroflumethiazide & Bendroflumethiazide, Aprinox, Neo-Naclex, Timolol \\
Sertraline & Sertraline, Lustral \\
Fluvastatin & Fluvastatin, Dorisin, Lescol, Luvinsta, Nandovar, Pinmactil \\
Budesonide & Budesonide, Aircort, Budeflam, Budelin, Budenofalk, DuoResp, Entocort, Pulmicort, Rhinocort, Symbicort \\
\hline
\end{tabular}


Appendix 4: List of generic and proprietary drug names for each confounder compound

\begin{tabular}{|c|c|}
\hline Substance Name & Drug Name \\
\hline Aspirin & Aspirin, Asasantin, Caprin, Co-codaprin, Micropirin, Migramax, Nu-Seals \\
\hline Digoxin & Digoxin, Lanoxin \\
\hline $\begin{array}{l}\text { Hormone Replacement } \\
\text { Therapy }\end{array}$ & $\begin{array}{l}\text { Angeliq, Bedol , Climagest , Climaval , Clinorette, Conjugated oestrogens, Crinone, Cyclogest, Elleste , Estraderm, } \\
\text { Estradiol, Estradiol , Estradot , Estragest, Estring, Estriol, Ethinylestradiol, Evorel , Femoston, Femseven, Gestone, } \\
\text { Indivina, Kliofem , Kliovance , Lubion , Lutigest, Novofem, Nuvelle, Oestrogel, Ovestin , Premarin , Pro-Juven, } \\
\text { Progesterone, Progynova, Prontogest, Sandrena, Serenity, Tridestra, Trisequens , Utrogestan , Vagifem , Zumenon }\end{array}$ \\
\hline Metformin & $\begin{array}{l}\text { Metformin, Alogliptin, Bolamyn, Competact, Diagemet, Eucreas, Glucient, Glucophage, Janumet, Jentadueto, } \\
\text { Komboglyze, Metabet, Metformin, Sukkarto, Synjardy, Vipdomet, Vokanamet, Xigduo }\end{array}$ \\
\hline Oral Contraceptive & 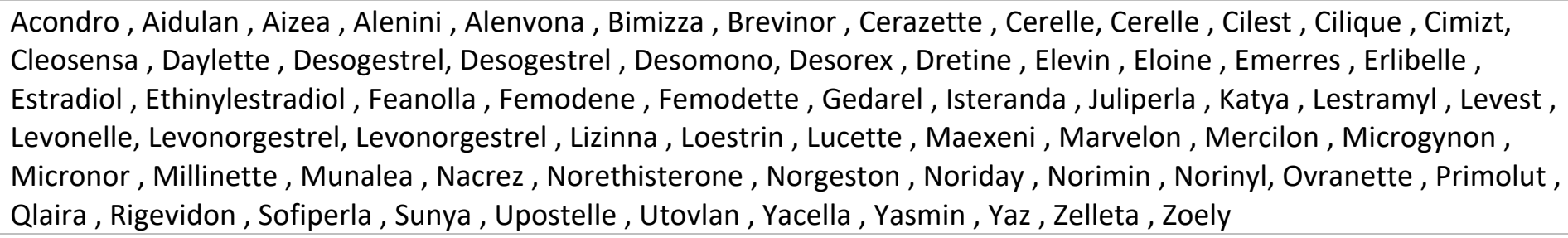 \\
\hline Statin & $\begin{array}{l}\text { Atorvastatin, Cholib, Crestor, Dorisin, Fluvastatin, Inegy, Lescol, Lipitor, Lipostat, Luvinsta, Pinmactil, Pravastatin, } \\
\text { Rosuvastatin, Simvador, Simvastatin, Stefluvin, Zocor }\end{array}$ \\
\hline
\end{tabular}




\begin{tabular}{|c|c|}
\hline Characteristic & Adjusted OR $(95 \% \mathrm{Cl})$ \\
\hline \multicolumn{2}{|l|}{ Smoking } \\
\hline No & Ref \\
\hline Ex & $1.04(0.98,1.10)$ \\
\hline Yes & $1.03(0.99,1.07)$ \\
\hline \multicolumn{2}{|l|}{ Alcohol } \\
\hline No & Ref \\
\hline Ex & $0.97(0.79,1.19)$ \\
\hline Yes & $1.10(1.06,1.15)$ \\
\hline \multicolumn{2}{|l|}{ Obesity } \\
\hline Normal & Ref \\
\hline Overweight & $1.02(0.98,1.06)$ \\
\hline Obese & $1.05(1.01,1.10)$ \\
\hline \multicolumn{2}{|l|}{ Deprivation Quintile } \\
\hline 1 (Least Deprived) & Ref \\
\hline 2 & $0.91(0.84,0.99)$ \\
\hline 3 & $0.82(0.75,0.90)$ \\
\hline 4 & $0.69(0.63,0.76)$ \\
\hline 5 (Most Deprived) & $0.54(0.48,0.61)$ \\
\hline \multicolumn{2}{|l|}{ Comorbidities } \\
\hline AIDS & $0.97(0.06,15.52)$ \\
\hline Cerebrovascular disease & $0.94(0.86,1.03)$ \\
\hline Chronic pulmonary disease & $0.99(0.95,1.03)$ \\
\hline Congestive heart disease & $1.02(0.90,1.17)$ \\
\hline Dementia & $0.96(0.78,1.18)$ \\
\hline Diabetes & $1.06(0.95,1.17)$ \\
\hline Diabetes with complications & $0.88(0.76,1.02)$ \\
\hline DCIS & $5.70(3.46,9.42)$ \\
\hline Hemiplegia & $1.07(0.73,1.58)$ \\
\hline Mild liver disease & $0.97(0.74,1.27)$ \\
\hline Mod liver disease & $1.35(0.65,2.77)$ \\
\hline Myocardial infarction & $1.05(0.93,1.19)$ \\
\hline Peptic ulcer disease & $1.02(0.93,1.13)$ \\
\hline Peripheral vascular disease & $0.95(0.83,1.08)$ \\
\hline Renal disease & $1.01(0.93,1.09)$ \\
\hline Rheumatological disease & $0.84(0.77,0.91)$ \\
\hline \multicolumn{2}{|l|}{ Confounder Medications } \\
\hline Aspirin & $1.01(0.96,1.06)$ \\
\hline Digoxin & $1.28(1.13,1.45)$ \\
\hline Hormone Replacement Therapy & $1.11(1.07,1.16)$ \\
\hline Metformin & $1.04(0.92,1.17)$ \\
\hline Oral Contraceptive & $1.14(1.06,1.22)$ \\
\hline Statin & $0.95(0.90,1.00)$ \\
\hline
\end{tabular}


Appendix 6: Breast cancer risk by level of medication use, NCDR recorded cases only

\begin{tabular}{|c|c|c|c|c|}
\hline Substance & Cases & Controls & $\begin{array}{c}\text { Unadjusted OR } \\
(95 \% \mathrm{Cl})\end{array}$ & $\begin{array}{c}\text { Adjusted OR } \\
(95 \% \mathrm{Cl})^{\dagger}\end{array}$ \\
\hline \multicolumn{5}{|l|}{ Meloxicam } \\
\hline Never & 17,565 (96.8\%) & 17,623 (97.1\%) & Ref & Ref \\
\hline Ever & $588(3.2 \%)$ & $530(2.9 \%)$ & $1.12(0.99,1.27)$ & $1.12(0.96,1.29)$ \\
\hline 1-365 DDDs ${ }^{\ddagger}$ & $497(2.7 \%)$ & $447(2.5 \%)$ & $1.13(0.98,1.29)$ & $1.09(0.92,1.28)$ \\
\hline$>365$ DDDs & 91 (0.5\%) & $83(0.5 \%)$ & $1.11(0.82,1.49)$ & $1.27(0.90,1.80)$ \\
\hline \multicolumn{5}{|l|}{ Azithromycin } \\
\hline Never & 18,045 (99.4\%) & 18,047 (99.4\%) & Ref & Ref \\
\hline Ever & $108(0.6 \%)$ & $106(0.6 \%)$ & $1.02(0.78,1.34)$ & $1.04(0.75,1.44)$ \\
\hline 1-365 DDDs & $107(0.6 \%)$ & $106(0.6 \%)$ & $1.01(0.77,1.33)$ & $1.03(0.74,1.42)$ \\
\hline$>365$ DDDs & $1(0.0 \%)$ & $0(0.0 \%)$ & N/A & $\mathrm{N} / \mathrm{A}$ \\
\hline \multicolumn{5}{|l|}{ Rizatriptan } \\
\hline Never & $18,078(99.6 \%)$ & 18,077 (99.6\%) & Ref & Ref \\
\hline Ever & 75 (0.4\%) & $76(0.4 \%)$ & $0.99(0.72,1.36)$ & $1.12(0.79,1.59)$ \\
\hline 1-365 DDDs & $74(0.4 \%)$ & 73 (0.4\%) & $1.01(0.73,1.40)$ & $1.14(0.80,1.63)$ \\
\hline >365 DDDs & $1(0.0 \%)$ & $3(0.0 \%)$ & $\mathrm{N} / \mathrm{A}$ & N/A \\
\hline \multicolumn{5}{|l|}{ Citalopram } \\
\hline Never & 17,019 (93.8\%) & 17,101 (94.2\%) & Ref & Ref \\
\hline Ever & $1,134(6.2 \%)$ & $1,052(5.8 \%)$ & $1.09(0.99,1.19)$ & $1.06(0.96,1.18)$ \\
\hline 1-365 DDDs & 819 (4.5\%) & $758(4.2 \%)$ & $1.09(0.98,1.21)$ & $1.04(0.92,1.17)$ \\
\hline >365 DDDs & 315 (1.7\%) & 294 (1.6\%) & $1.08(0.92,1.27)$ & $1.14(0.94,1.38)$ \\
\hline \multicolumn{5}{|l|}{ Rosiglitazone } \\
\hline Never & 18,059 (99.5\%) & 18,065 (99.5\%) & Ref & Ref \\
\hline Ever & $94(0.5 \%)$ & $88(0.5 \%)$ & $1.07(0.80,1.43)$ & $0.88(0.62,1.26)$ \\
\hline 1-365 DDDs & $54(0.3 \%)$ & $38(0.2 \%)$ & $1.42(0.94,2.15)$ & $1.11(0.67,1.82)$ \\
\hline$>365$ DDDs & $40(0.2 \%)$ & $50(0.3 \%)$ & $0.80(0.53,1.21)$ & $0.73(0.46,1.16)$ \\
\hline \multicolumn{5}{|l|}{ Verapamil } \\
\hline Never & $17,968(99.0 \%)$ & 17,991 (99.1\%) & Ref & Ref \\
\hline Ever & 185 (1.0\%) & $162(0.9 \%)$ & $1.14(0.93,1.42)$ & $1.11(0.86,1.44)$ \\
\hline 1-365 DDDs & $94(0.5 \%)$ & $74(0.4 \%)$ & $1.27(0.94,1.72)$ & $1.17(0.81,1.70)$ \\
\hline$>365$ DDDs & $91(0.5 \%)$ & $88(0.5 \%)$ & $1.04(0.77,1.39)$ & $1.06(0.74,1.52)$ \\
\hline \multicolumn{5}{|c|}{ Bendroflumethiazide } \\
\hline Never & $14,448(79.6 \%)$ & 14,665 (80.8\%) & Ref & Ref \\
\hline Ever & $3,705(20.4 \%)$ & $3,488(19.2 \%)$ & $1.09(1.03,1.15)$ & $1.10(1.03,1.18)$ \\
\hline 1-365 DDDs & $1,272(7.0 \%)$ & $1,187(6.5 \%)$ & $1.10(1.01,1.19)$ & $1.09(0.98,1.21)$ \\
\hline >365 DDDs & $2,433(13.4 \%)$ & $2,301(12.7 \%)$ & $1.09(1.02,1.16)$ & $1.11(1.02,1.20)$ \\
\hline \multicolumn{5}{|l|}{ Sertraline } \\
\hline Never & $17,714(97.6 \%)$ & 17,717 (97.6\%) & Ref & Ref \\
\hline Ever & 439 (2.4\%) & $436(2.4 \%)$ & $1.01(0.88,1.15)$ & $1.03(0.88,1.22)$ \\
\hline 1-365 DDDs & $293(1.6 \%)$ & $296(1.6 \%)$ & $0.99(0.84,1.17)$ & $1.01(0.83,1.23)$ \\
\hline$>365$ DDDs & $146(0.8 \%)$ & $140(0.8 \%)$ & $1.04(0.83,1.32)$ & $1.08(0.82,1.43)$ \\
\hline \multicolumn{5}{|l|}{ Fluvastatin } \\
\hline Never & $18,074(99.6 \%)$ & $18,088(99.6 \%)$ & Ref & Ref \\
\hline Ever & $79(0.4 \%)$ & $65(0.4 \%)$ & $1.23(0.88,1.71)$ & $1.17(0.79,1.73)$ \\
\hline 1-365 DDDs & $54(0.3 \%)$ & $39(0.2 \%)$ & $1.40(0.92,2.14)$ & $1.19(0.74,1.92)$ \\
\hline$>365$ DDDs & $25(0.1 \%)$ & $26(0.1 \%)$ & $0.97(0.56,1.68)$ & $1.12(0.56,2.23)$ \\
\hline \multicolumn{5}{|l|}{ Budesonide } \\
\hline Never & $17,657(97.3 \%)$ & 17,637 (97.2\%) & Ref & Ref \\
\hline Ever & $496(2.7 \%)$ & $516(2.8 \%)$ & $0.96(0.85,1.09)$ & $0.90(0.77,1.06)$ \\
\hline 1-365 DDDs & $348(1.9 \%)$ & $367(2.0 \%)$ & $0.95(0.81,1.10)$ & $0.84(0.70,1.01)$ \\
\hline$>365$ DDDs & $148(0.8 \%)$ & $149(0.8 \%)$ & $0.99(0.79,1.25)$ & $1.08(0.82,1.42)$ \\
\hline
\end{tabular}

${ }^{\dagger}$ Adjusted for comorbidities (AIDS, cerebrovascular disease, chronic pulmonary disease, congestive heart disease, dementia, diabetes, diabetes with complications, ductal carcinoma in situ, hemiplegia, mild liver disease, moderate liver disease, myocardial infarction, peptic ulcer disease, peripheral vascular disease, renal disease, rheumatological disease), confounder medications (aspirin, digoxin, hormone replacement therapy, metformin, oral contraceptive, statin), deprivation, smoking status, alcohol consumption and obesity. Additionally conditioned on age, GP practice and year of diagnosis

$\ddagger$ Defined daily dose 


\section{Appendix 7: Stratified analysis of breast cancer risk by ever medication use, NCDR and GP recorded cases}

\begin{tabular}{|c|c|c|c|c|c|}
\hline & Cases & Controls & $\begin{array}{c}\text { Unadjusted OR } \\
(95 \% \mathrm{Cl})\end{array}$ & $\begin{array}{c}\text { Adjusted OR } \\
(95 \% \mathrm{Cl})^{\dagger}\end{array}$ & $\begin{array}{c}\text { Interaction } \\
\text { Test } \\
\end{array}$ \\
\hline \multicolumn{6}{|l|}{ Meloxicam } \\
\hline Menopause: age $<50$ & $92(1.1 \%)$ & $92(1.1 \%)$ & $1.00(0.74,1.34)$ & $0.85(0.59,1.21)$ & 0.186 \\
\hline Menopause: age $>50$ & $1,512(4.1 \%)$ & 1,442 (3.9\%) & $1.05(0.98,1.14)$ & $1.05(0.96,1.15)$ & \\
\hline Assumed ER Status: Negative & $372(3.5 \%)$ & 347 (3.3\%) & $1.08(0.93,1.26)$ & $1.08(0.90,1.29)$ & 0.524 \\
\hline Assumed ER Status: Positive & $1,232(3.6 \%)$ & $1,187(3.4 \%)$ & $1.04(0.96,1.13)$ & $1.03(0.93,1.14)$ & \\
\hline \multicolumn{6}{|l|}{ Azithromycin } \\
\hline Menopause: Pre & $58(0.7 \%)$ & $64(0.8 \%)$ & $0.90(0.63,1.30)$ & $0.96(0.63,1.46)$ & 0.930 \\
\hline Menopause: Post & $276(0.8 \%)$ & $301(0.8 \%)$ & $0.91(0.77,1.08)$ & $0.92(0.76,1.12)$ & \\
\hline ER Status: Negative & $75(0.7 \%)$ & $78(0.7 \%)$ & $0.96(0.69,1.33)$ & $0.96(0.65,1.42)$ & 0.907 \\
\hline ER Status: Positive & $259(0.7 \%)$ & $287(0.8 \%)$ & $0.90(0.75,1.07)$ & $0.93(0.76,1.13)$ & \\
\hline \multicolumn{6}{|l|}{ Rizatriptan } \\
\hline Menopause: Pre & $73(0.9 \%)$ & $81(1.0 \%)$ & $0.90(0.65,1.24)$ & $1.21(0.83,1.78)$ & 0.603 \\
\hline Menopause: Post & $169(0.5 \%)$ & $162(0.4 \%)$ & $1.04(0.84,1.30)$ & $1.08(0.85,1.38)$ & \\
\hline ER Status: Negative & $63(0.6 \%)$ & $60(0.6 \%)$ & $1.05(0.73,1.51)$ & $1.11(0.74,1.66)$ & 0.926 \\
\hline ER Status: Positive & $179(0.5 \%)$ & $183(0.5 \%)$ & $0.98(0.79,1.20)$ & $1.11(0.88,1.41)$ & \\
\hline \multicolumn{6}{|l|}{ Citalopram } \\
\hline Menopause: Pre & 846 (10.0\%) & 849 (10.1\%) & $1.00(0.90,1.10)$ & $0.98(0.87,1.11)$ & 0.431 \\
\hline Menopause: Post & $3,008(8.2 \%)$ & $2,950(8.0 \%)$ & $1.02(0.97,1.08)$ & $1.02(0.96,1.09)$ & \\
\hline ER Status: Negative & 989 (9.4\%) & $967(9.2 \%)$ & $1.03(0.93,1.13)$ & $1.02(0.91,1.14)$ & 0.831 \\
\hline ER Status: Positive & $2,865(8.3 \%)$ & $2,832(8.2 \%)$ & $1.01(0.96,1.07)$ & $1.01(0.94,1.08)$ & \\
\hline \multicolumn{6}{|l|}{ Rosiglitazone } \\
\hline Menopause: Pre & $5(0.1 \%)$ & $12(0.1 \%)$ & N/A & N/A & $N / A^{\ddagger}$ \\
\hline Menopause: Post & $249(0.7 \%)$ & $246(0.7 \%)$ & $1.01(0.85,1.21)$ & $1.03(0.83,1.27)$ & \\
\hline ER Status: Negative & $61(0.6 \%)$ & $60(0.6 \%)$ & $1.02(0.71,1.45)$ & $0.97(0.64,1.47)$ & 0.911 \\
\hline ER Status: Positive & $193(0.6 \%)$ & $198(0.6 \%)$ & $0.97(0.80,1.19)$ & $1.00(0.79,1.26)$ & \\
\hline \multicolumn{6}{|l|}{ Verapamil } \\
\hline Menopause: Pre & $13(0.2 \%)$ & $14(0.2 \%)$ & $0.93(0.44,1.98)$ & $0.65(0.26,1.61)$ & 0.263 \\
\hline Menopause: Post & $463(1.3 \%)$ & $380(1.0 \%)$ & $1.22(1.07,1.40)$ & $1.18(1.00,1.39)$ & \\
\hline ER Status: Negative & $91(0.9 \%)$ & $83(0.8 \%)$ & $1.10(0.81,1.48)$ & $1.02(0.71,1.46)$ & 0.480 \\
\hline ER Status: Positive & $385(1.1 \%)$ & $311(0.9 \%)$ & $1.24(1.07,1.45)$ & $1.20(1.00,1.43)$ & \\
\hline \multicolumn{6}{|l|}{ Bendroflumethiazide } \\
\hline Menopause: Pre & $322(3.8 \%)$ & $294(3.5 \%)$ & $1.10(0.94,1.29)$ & $1.23(1.01,1.49)$ & 0.845 \\
\hline Menopause: Post & $9,042(24.6 \%)$ & $8,506(23.2 \%)$ & $1.09(1.05,1.13)$ & $1.10(1.05,1.14)$ & \\
\hline ER Status: Negative & 1,935 (18.4\%) & $1,884(17.9 \%)$ & $1.04(0.96,1.12)$ & $1.08(0.99,1.18)$ & 0.541 \\
\hline ER Status: Positive & 7,429 (21.4\%) & 6,916 (20.0\%) & $1.11(1.07,1.15)$ & $1.11(1.06,1.17)$ & \\
\hline \multicolumn{6}{|l|}{ Sertraline } \\
\hline Menopause: Pre & $289(3.4 \%)$ & $299(3.5 \%)$ & $0.96(0.82,1.14)$ & $0.98(0.81,1.20)$ & 0.671 \\
\hline Menopause: Post & $1,074(2.9 \%)$ & $1,058(2.9 \%)$ & $1.02(0.93,1.11)$ & $1.02(0.92,1.13)$ & \\
\hline ER Status: Negative & $318(3.0 \%)$ & $315(3.0 \%)$ & $1.01(0.86,1.19)$ & $1.04(0.86,1.26)$ & 0.813 \\
\hline ER Status: Positive & $1,045(3.0 \%)$ & $1,042(3.0 \%)$ & $1.00(0.92,1.10)$ & $1.01(0.91,1.11)$ & \\
\hline \multicolumn{6}{|l|}{ Fluvastatin } \\
\hline Menopause: Pre & $0(0.0 \%)$ & $3(0.0 \%)$ & N/A & $\mathrm{N} / \mathrm{A}$ & N/A \\
\hline Menopause: Post & $203(0.6 \%)$ & $199(0.5 \%)$ & $1.02(0.84,1.25)$ & $0.99(0.79,1.25)$ & \\
\hline ER Status: Negative & $47(0.4 \%)$ & $47(0.4 \%)$ & $1.00(0.67,1.50)$ & $1.19(0.74,1.91)$ & 0.277 \\
\hline ER Status: Positive & $156(0.5 \%)$ & $155(0.4 \%)$ & $1.01(0.80,1.26)$ & $0.92(0.71,1.19)$ & \\
\hline \multicolumn{6}{|l|}{ Budesonide } \\
\hline Menopause: Pre & $216(2.6 \%)$ & $230(2.7 \%)$ & $0.94(0.77,1.13)$ & $0.93(0.73,1.18)$ & 0.389 \\
\hline Menopause: Post & $1,353(3.7 \%)$ & $1,382(3.8 \%)$ & $0.98(0.91,1.06)$ & $0.96(0.87,1.05)$ & \\
\hline ER Status: Negative & 339 (3.2\%) & 399 (3.8\%) & $0.84(0.73,0.98)$ & $0.83(0.70,0.99)$ & 0.050 \\
\hline ER Status: Positive & $1,230(3.5 \%)$ & $1,213(3.5 \%)$ & $1.01(0.94,1.10)$ & $1.00(0.90,1.10)$ & \\
\hline
\end{tabular}

${ }^{\dagger}$ Adjusted for comorbidities (AIDS, cerebrovascular disease, chronic pulmonary disease, congestive heart disease, dementia, diabetes, diabetes with complications, ductal carcinoma in situ, hemiplegia, mild liver disease, moderate liver disease, myocardial infarction, peptic ulcer disease, peripheral vascular disease, renal disease, rheumatological disease), confounder medications (aspirin, digoxin, hormone replacement therapy, metformin, oral contraceptive, statin), deprivation, smoking status, alcohol consumption and obesity. Additionally conditioned on age, GP practice and year of diagnosis

FExcluded due to low use of medication in subgroup 